\title{
Clinicoepidemiological findings of childhood brucellosis in a tertiary care center in Central Anatolia: with the emphasis of hematological findings
}

\author{
Ayşe $\operatorname{Kaman}^{1 \odot}$, Fatma Nur Öz ${ }^{1 \oplus}$, Ali Fettah ${ }^{2 \odot}$, Sevgi Yaşar Durmuş ${ }^{1 \oplus}$, \\ Türkan Aydın Teke ${ }^{1 \odot}$, Gönül Tanır ${ }^{1 \odot}$ \\ Departments of ${ }^{1}$ Pediatric Infectious Disease and ${ }^{2}$ Pediatric Hematology and Oncology, Dr. Sami Ulus Maternity and Children's Health \\ and Diseases Training and Research Hospital, Ankara, Turkey.
}

\begin{abstract}
Background. Human brucellosis is one of the most widespread zoonotic diseases that are presented with predominantly hematological manifestations. We aimed to evaluate the hematological findings of childhood brucellosis and to determine the predictive clinical findings and laboratory tests that might be related to hematologic involvement.
\end{abstract}

Methods. We retrospectively analyzed the medical records of children with brucellosis between 1 January 2005 and 31 December 2018. We compared predictive clinical and physical examination findings and laboratory tests in patients with and without hematological involvement.

Results. A total of 212 patients (127 boys $(59.9 \%)$ ) with a mean age of $9.4 \pm 4.7$ years were evaluated in this study. Blood cultures were performed in $161(75.9 \%)$ patients and Brucella spp were isolated in $70(43.4 \%)$ of them. Ninety-two (43.4\%) patients had hematological involvement at least in one series. Anemia was detected in $66(31.7 \%)$ patients, leukopenia in $22(10.6 \%)$ and thrombocytopenia in $10(4.8 \%)$. Four patients $(1.9 \%)$ had pancytopenia. Age distrubutions of the patients with and without hematological involvement were similar $(\mathrm{p}=0.6)$. In patients presented with fever, hepatomegaly and splenomegaly, hematologic involvement was significantly higher $(\mathrm{p}<0.05)$. Hematological involvement was higher in patients who had elevated aspartate aminotransferase and alanine aminotransferase concentrations $(p<0.05)$. Hematological involvement was higher in patients with positive blood culture $(\mathrm{p}=0.005)$. Six patients $(2.8 \%)$ were treated with intravenous immunoglobulin at $1000 \mathrm{mg} / \mathrm{kg} /$ day for two days in addition to anti-brucellosis treatment.

Conclusions. Hematological involvement in brucellosis is a common finding regardless of age, especially in febrile, bacteremic patients and in patients who had hepatosplenomegaly and elevated liver enzymes. Anemia is the most common hematological abnormality.

Key words: brucellosis, children, cytopenia, hematological findings.

Human brucellosis is one of the most widespread zoonotic diseases and a public health problem in many countries of the Mediterranean and Middle East where bovine brucellosis has

$\triangle$ Ayşe Kaman

ayse092003@yahoo.com

Received 27th October 2020, revised 15th October 2021, accepted 7th November 2021

This study was presented as an oral presentation in the12th National Pediatric Infectious Disease and Immunization Congress, 27-31 March 2019, Antalya, Turkey. not been controlled. It can affect people at any age including children. Approximately $20-30 \%$ of cases are diagnosed during childhood. ${ }^{1-3}$ Humans can acquire infections via consumption of infected unpasteurized milk and milk products or direct contact with infected animals, secretions and carcasses. Brucellosis is a multisystemic disease which can be presented with various non-specific clinical signs. The most common clinical manifestations include arthralgia, fever, sweating, weight loss, fatigue, and anorexia. ${ }^{1}$ Some of these 
patients can be presented with hematological manifestations such as mild anemia, leukopenia and less frequently pancytopenia and thrombocytopenia. Brucellosis may mimic many hematologic diseases, especially in patients presenting predominantly with hematological findings. ${ }^{2,4}$

In this study, we aimed to evaluate the hematological findings of childhood brucellosis and to determine the predicting clinical and physical examination findings and laboratory tests that might be related to hematologic involvement in the setting of a tertiary care pediatric hospital.

\section{Material and Methods}

We retrospectively analyzed the medical records of children with brucellosis who were admitted to a referral tertiary care pediatric hospital between 1 January 2005 and 31 December 2018. This study was conducted in compliance with the ethical principles according to the Declaration of Helsinki, and it was approved by the Dr. Sami Ulus Maternity and Children's Health and Diseases Training and Research Hospital Institutional Review Board (Number: 2019/8). Data regarding age, sex, family history of brucellosis, occupation, fresh milk product consumption history, clinical complaints, physical examination findings and laboratory results were recorded. Organomegaly was assessed with physical examination. Laboratory tests including complete blood count [total leukocyte, absolute neutrophil, absolute lymphocyte, platelet count and mean platelet volume (MPV)], C-reactive protein (CRP), erythrocyte sedimentaton rate (ESR), serum aspartate aminotransferase (AST) and alanine aminotransferase (ALT) concentrations, blood culture, brucella agglutination tests, bone marrow aspiration smear results if had been applicated and treatment data were evaluated. Brucellosis was diagnosed on the basis of epidemiological and clinical findings, together with positive serum agglutination test (SAT) $\geq 1 / 160$ titers and/or Brucella immune capture test with Coombs $\geq 1 / 160$ titers and/or isolation of Brucella spp. from blood culture. Agglutination titer range was set at $1 / 20-1 / 5120$ for each serum sample to avoid false negative results in consequence of prozone effect. Hematological findings were defined as follows: Thrombocytopenia, a platelet count $<150.000 /$ $\mu \mathrm{L}$, leukopenia and anemia, a level lower than age-determined references. Pancytopenia was defined as abnormally low counts of white cells, platelets and low level of hemoglobin in the same patient. ${ }^{5}$

Data were entered to a database and statistical analyses were performed using IBM SPSS Statistics (IBM Corp. Released 2012. IBM SPSS Statistics for Windows, Version 21.0. Armonk, NY: IBM Corp.). The variables were investigated using visual and analytical methods (Kolmogrov-Simirnov/Shapira-Wilk test) to determine whether or not they are normally distributed. Descriptive analyses were presented using means \pm standard deviations for normally distributed variables and as medians (minimum-maximum) for the non-normally distributed and ordinal variables. Frequencies were given to summarize the categorical variables. The chi-square test or Fisher's exact test was used to compare patients with or without hematological involvement. The correlation coefficients and their significance were calculated using the Pearson test between SAT titer and mean platelet volume. A p-value less than 0.05 was considered a statistically significant result.

\section{Results}

A total of 212 patients [127 boys (59.9\%)] diagnosed with brucellosis were evaluated in this study. Age distribution was from one day old neonate to 17.9 years. Median age of the patients was 9.4 years (SD 4.7 years) and 10.09 years (IQR: 5.35 years-13.3 years). Four (1.8\%) patients were younger than one year of age (one patient was a preterm neonate, one patient an exclusively breast-fed young infant, two patients complementarily fed babies including 
unpasteurized cheese), 45 patients were between 1-5 years, 87 patients were between 5-12 years, and 76 patients were $\geq 12$ years. None of the patients had a known hematologic disease. One hundred and twenty eight (60.4\%) patients were hospitalized for a mean duration of $11 \pm 6.7$ days. A total of $183(86.3 \%)$ patients had a history of consuming unpasteurized milk and dairy products. At least one parent of 121 patients $(57.1 \%)$ were working in animal breeding and had intimate contact with sheep and/or cows. Eighty-four (39.6\%) patients had positive family history for brucellosis. The symptoms and physical examination findings were shown in Table I. Median duration of fever was 15 days (range 1-365 days). The most commonly involved joint was knee in $21(65.6 \%)$ patients, followed by ankle in seven $(21.9 \%)$ patients and hip in four $(12.5 \%)$ patients. Nine $(75.0 \%)$ patients had cervical, two $(16.7 \%)$ had inguinal, and one $(8.3 \%)$ had mesenteric lymphadenopathy. Blood cultures were performed in 161 (75.9\%) patients and Brucella spp were isolated in 70 (43.4\%) of them. Serum agglutination test titers at presentation were $\geq 1 / 160$ in 201 patients $(94.8 \%)$. Ten $(4.7 \%)$ patients with SAT titers of $<1 / 160$ were diagnosed with positive blood culture.

Table I. The clinical symptoms and physical examination findings of patients with brucellosis.

\begin{tabular}{lcc}
\hline & Patient number & $\%$ \\
\hline Clinical symptoms & 154 & 72.6 \\
Arthralgia & 119 & 56.1 \\
Fever & 46 & 21.7 \\
Weight loss & 30 & 14.2 \\
Night sweats & 36 & 17 \\
Arthritis & 17 & 8 \\
Headache & 17 & 8 \\
Abdominal pain & & \\
Physical examination findings & 38 & 17.9 \\
Hepatomegaly & 35 & 17.5 \\
Fever & 32 & 15.1 \\
Arthritis & 28 & 13.2 \\
Splenomegaly & 12 & 5.7 \\
Lymphadenopathy & & \\
\hline
\end{tabular}

Ninety-two (43.4\%) patients had hematological involvement at least in one lineage. The initial complete blood count findings of patients were summarized in Table II. On admission, anemia was detected in $66(31.7 \%)$ patients, leukopenia was detected in $22(10.6 \%)$ patients [14 $(6.7 \%)$ neutropenia, 14 (6.7\%) lymphopenia], and thrombocytopenia was detected in $10(4.8 \%)$ patients. Four patients $(1.9 \%$ ) had pancytopenia. The epidemiological and laboratory findings of patients presenting with pancytopenia were shown in Table III. Aspartate aminotransferase and ALT levels were $\geq 40 \mathrm{IU} / \mathrm{L}$ in 69 (32.5\%) and in $55(25.9 \%)$ patients, respectively.

The mean age of patients with and without hematological involvement were 9.6 \pm 4.5 years and $9.3 \pm 4.8$ years, respectively $(p=0.6)$. Hematologic involvement was higher in patients with fever $(p<0.001)$. There was no association between duration of fever and hematologic involvement $(\mathrm{p}=0.68)$. In patients who had hepatomegaly and splenomegaly, hematologic involvement was statistically higher ( $\mathrm{p}=0.001$ and $\mathrm{p}=0.005$, respectively). Hematological involvement was also higher in those who had elevated AST and ALT levels $(\mathrm{p}<0.05)$. The presence of hepatomegaly and splenomegaly, results of blood cultures and transaminase concentrations of patients with and without hematologic involvement were shown in Table IV. Mean platelet volume was $8.1 \pm 0.95 \mathrm{fL}$, and there was no correlation between SAT titer and mean platelet volume $(\mathrm{r}=-0.02, \mathrm{p}=0.7)$. It was found that SAT titers were not correlated with the presence of hematologic findings $(p=0.55)$. Hematological involvement was higher in patients with positive blood culture $(p=0.005)$. Bone marrow aspiration was performed in 14 (15.2\%) patients with hematological impairement. In one patient with pancytopenia, the bone marrow aspiration revealed multiple hemophagocytic histiocytes, in four patients (one patient with leukopenia and thrombocytopenia, three patients with anemia and leukopenia) revealed a few number of hemophagocytic histiocytes. Two patients with pancytopenia had normal bone marrow 
Table II. The initial complete blood count findings of patients.

\begin{tabular}{lccc}
\hline Parameter & $\begin{array}{c}\text { All patients } \\
(\text { mean } \pm \mathrm{SD})\end{array}$ & $\begin{array}{c}\text { Hematologic involvement } \\
\text { present } \\
(\text { mean } \pm \mathrm{SD})\end{array}$ & $\begin{array}{c}\text { Hematologic involvement } \\
\text { absent } \\
(\text { mean } \pm \mathrm{SD})\end{array}$ \\
\hline Hemoglobin $(\mathrm{g} / \mathrm{dL})$ & $12 \pm 1.4$ & $10.5 \pm 1.1$ & $12.7 \pm 0.9$ \\
Total leukocyte $\left(/ \mathrm{mm}^{3}\right)$ & $7450 \pm 4735$ & $3700 \pm 916$ & $7907 \pm 4810$ \\
Absolut neutrophil $\left(/ \mathrm{mm}^{3}\right)$ & $3267 \pm 1965$ & $1067 \pm 330$ & $3471 \pm 1929$ \\
Absolute lymphocyte $\left(/ \mathrm{mm}^{3}\right)$ & $3411 \pm 2686$ & $1321 \pm 315$ & $3605 \pm 2727$ \\
Platelet $\left(/ \mathrm{mm}^{3}\right)$ & $284.509 \pm 97.585$ & $93.785 \pm 37.529$ & $297.994 \pm 85.667$ \\
\hline
\end{tabular}

Table III. Epidemiological and laboratory findings of patients with pancytopenia.

\begin{tabular}{|c|c|c|c|c|c|c|c|c|c|c|c|}
\hline $\begin{array}{l}\text { Patient } \\
\text { number }\end{array}$ & $\begin{array}{c}\text { Age } \\
\text { (month) }\end{array}$ & Gender & $\begin{array}{l}\mathrm{Hb} \\
\mathrm{g} / \mathrm{dL}\end{array}$ & $\begin{array}{l}\text { WBC } \\
/ \mathrm{mm}^{3}\end{array}$ & $\begin{array}{l}\text { Nuetrophil } \\
/ \mathrm{mm}^{3}\end{array}$ & $\begin{array}{l}\text { Lymphocyte } \\
\qquad / \mathrm{mm}^{3}\end{array}$ & $\begin{array}{l}\text { Platelet } \\
/ \mathrm{mm}^{3}\end{array}$ & $\begin{array}{c}\text { ESR } \\
\mathrm{mm} / \mathrm{h}\end{array}$ & $\begin{array}{l}\mathrm{CRP} \\
\mathrm{mg} / \mathrm{L}\end{array}$ & SAT & $\begin{array}{l}\text { Blood } \\
\text { culture }\end{array}$ \\
\hline 1 & 145 & $\mathrm{~F}$ & 11.4 & 2600 & 900 & 1410 & 140.000 & 28 & 101 & $1 / 320$ & $\begin{array}{l}\text { Brucella } \\
\text { spp. }\end{array}$ \\
\hline 2 & 91 & M & 8.5 & 1800 & 830 & 710 & 69.000 & - & 39 & $1 / 640$ & $\begin{array}{l}\text { Brucella } \\
\text { spp. }\end{array}$ \\
\hline 3 & 173 & $\mathrm{~F}$ & 10.8 & 2900 & 1400 & 1000 & 70.000 & 120 & 77 & $1 / 5120$ & $\begin{array}{l}\text { No } \\
\text { growth }\end{array}$ \\
\hline 4 & 178 & F & 9.5 & 1800 & 770 & 930 & 62.000 & 30 & 11 & $1 / 640$ & $\begin{array}{l}\text { Brucella } \\
\text { spp. }\end{array}$ \\
\hline
\end{tabular}

Hb: hemoglobin, WBC: white blood cell, ESR: erythcyte sedimentaton rate, CRP: C-reactive protein, SAT: serum agglutination test

Table IV. Hepatomegaly, splenomegaly, transaminase and blood culture results in patients with and without hematologic involvement.

\begin{tabular}{lccc}
\hline & $\begin{array}{c}\text { Hematologic involvement present } \\
\mathrm{n} / \%\end{array}$ & $\begin{array}{c}\text { Hematogic involvement absent } \\
\mathrm{n} / \%\end{array}$ & $\mathrm{p}$ value \\
\hline $\begin{array}{l}\text { Hepatomegaly } \\
\text { Positive }\end{array}$ & $26(68.4 \%)$ & $12(31.6 \%)$ & \\
$\quad$ Negative & $66(37.9 \%)$ & $108(62.1 \%)$ & $\mathrm{p}=0.001$ \\
$\begin{array}{l}\text { Splenomegaly } \\
\quad \text { Positive }\end{array}$ & $19(67.9 \%)$ & $9(32.1 \%)$ & \\
$\quad$ Negative & $72(39.3 \%)$ & $111(60.7 \%)$ & $\mathrm{p}=0.005$ \\
ALT & $58(37.9 \%)$ & $95(62.1 \%)$ & \\
$\quad$ Normal & $33(60 \%)$ & $22(40 \%)$ & $\mathrm{p}=0.005$ \\
$\quad>40$ IU/L & & & \\
AST & $49(35.3 \%)$ & $90(64.7 \%)$ & $\mathrm{p}<0.001$ \\
$\quad$ Normal & $42(60.9 \%)$ & $27(39.1 \%)$ & \\
$\quad>40$ IU/L & & & $\mathrm{p}=0.005$ \\
Blood culture & $41(58.6 \%)$ & $29(41.4 \%)$ & \\
$\quad$ Brucella spp. & $33(36.3 \%)$ & $58(63.7 \%)$ & \\
$\quad$ No growth & & & \\
\hline AST & & & \\
\hline
\end{tabular}

AST: aspartate aminotransferase, ALT: alanine aminotransferase 
aspiration smears. All of the patients were treated with combination regimens (doxycycline plus rifampicin for patients older than eight years and cotrimoxazole plus rifampicin for those younger than eight years). Six patients (2.8\%) were treated with intravenous immunoglobulin (IVIg) $(1 \mathrm{~g} / \mathrm{kg} /$ day, for two days) in addition to anti-brucellosis treatment.

\section{Discussion}

In the present study, anemia was found as the most common hematological finding of brucellosis followed by leukopenia, thrombocytopenia, and pancytopenia. We found that the presence of hematological involvement was not affected by age, but patients who had fever, hepatosplenomegaly, positive blood culture for Brucella spp. and patients with elevated liver transaminase had higher rates of hematological involvement in brucellosis.

Worldwide incidence of brucellosis in endemic countries varies from $<0.01$ to $>200$ per 100000 population. ${ }^{6,7}$ In 2017, 381 confirmed cases of human brucellosis were reported in 20 European Union (EU) countries, with a rate of 0.10 cases per 100.000 population. The highest numbers of confirmed cases were reported in Greece, Italy and Spain that accounted for $67.2 \%$ of all confirmed cases in EU countries in that year. ${ }^{8}$ In Turkey, brucellosis remains a major public health issue, because the majority of people live in rural areas and they are engaged in animal husbandry. ${ }^{1}$ According to the Turkish Public Health Institution data, brucellosis affects 5.000 to 10.000 people each year and causes significant morbidity. ${ }^{9}$ It has been reported that brucellosis often affects children aged 5 to 15 years of age in different pediatric studies. ${ }^{1,10,11}$ A study conducted on 496 children with brucellosis in Eastern Turkey, showed that patients' age ranged from 1-16 years with a mean age of $10.0 \pm 3.95$ years. Half of the children were over 10 years of age and the male/female ratio was 1.5. ${ }^{12}$ In an another study including children with brucellosis living in central Blacksea region, $80.8 \%$ of patients were male and mean age was 11 years (range, 2-17 years). ${ }^{11}$ In the present study male gender dominance and mean age of patients were similar with those reported in previous pediatric studies.

In endemic areas, it is known that consumption of raw milk and dairy products is the main source for childhood brucellosis. Direct contact with infected animal is a possible acquision route of infection in older children whose families are engaged in animal husbandry. ${ }^{1,13}$ The majority of our patients had a history for consumption of unpasteurized milk, suggesting that this was the most common route of acquisition in this setting. Although human to human transmission is rare, cases of neonatal infection have raised the possibility of transplacental transmission. Furthermore, breastfed infants whose mothers have not been treated adequately might have been infected with Brucella spp. via human milk. ${ }^{14,15}$ We thought that one of our patients who was a preterm neonate had acquired brucellosis through transplacental route. Furthermore, there another patient acquired brucellosis via breast feeding in our series.

Brusellosis in pediatric patients may have a wide variety of nonspecific clinical presentations. Patients may present with fever, sweats, malaise, anorexia, weight loss, arthralgias, myalgias, headache, and abdominal pain., 41,16,17 In a large study including 496 children $(79.8 \%$ male), the most common symptoms were reported as arthralgia (46.2\%), fever (32.1\%) and abdominal pain $(17.1 \%)$ and the most common physical examination findings were arthritis (10.1\%), splenomegaly $(2.2 \%)$ and hepatomegaly $(1.8 \%)$, respectively. ${ }^{12}$ In a study from China, 88 children and 354 adult patients with male predominance were included. The authors demonstrated that fever was the most comon symptom in both children and adults $(82.9 \%$ vs $61.5 \%$, respectively), followed by joint pain, fatigue, anorexia and low back pain. ${ }^{10}$ In our study, as reported in previous studies, the most common symptoms were arthralgia and fever and the most common physical examination findings were hepatomegaly and arthritis. 
In the course of childhood brucellosis hematological complications are well known. Mild anemia and leukopenia have been reported mostly during the course of acute brucellosis. ${ }^{1,2,4,17}$ A comprehensive study including children living in an endemic area for brucellosis in Turkey analysed the hematologic manifestations of 622 patients. Hematologic involvement was observed in 292 patients (46.9\%). The most common hematologic involvement was anemia $(28.6 \%)$, followed by thrombocytopenia $(16 \%)$ and leukopenia [13.9\% (neutropenia 8\%, lymphopenia $8.8 \%$ )]. Pancytopenia was observed in $7.7 \%$ of patients. ${ }^{1}$ The incidence of anemia has been reported as $13.3 \%-55 \%$ in different pediatric series. ${ }^{1,12,18-20}$ In the present study anemia was the most common hemeatologic finding of brucellosis. We used hemoglobin levels determined for age to be able to make an objective evaluation when describing hematological findings like most other studies. In a pediatric study evaluating the hematological findings of brucellosis, cytopenia at least in one blood cell lineage detected in $41.9 \%$ of the patients, leukopenia in $28.2 \%$, thrombocytopenia in $14.5 \%$, anemia in $13.3 \%$, and pancytopenia in $13.3 \%$. Anemia had not been found as the most common hematological finding of brucellosis in this study in contrast to other pediatric studies. Authors thought that, this difference may be a result of choosing relatively low cut-off for hemoglobin levels of $10 \mathrm{mg} / \mathrm{dl}$ in order to minimize the anemia cases misrelated to brucellosis. ${ }^{18}$ Moderate to severe leukopenia and thrombocytopenia as well as normal leukocyte and thrombocyte counts in patients with brucellosis were reported.,12,18,19,21 On the contrary of leukopenia predominance in previous reports, in a prospective case-control study including 100 brucellosis patients and 100 healthy individuals, the authors found that WBC, CRP and neutrophil counts were significantly higher in the brucellosis group. As a result of this study, they concluded that the most significant laboratory findings of brucellosis were increased number of WBC, while decreased numbers of thrombocytes and lymphocytes. ${ }^{22}$
Pancytopenia and severe thrombocytopenia or isolated thrombocytopenia resulting in bleeding has rarely been reported in the course of brucellosis. ${ }^{18,21,23}$ The pathogenesis of thrombocytopenia during brucellosis may be multifactorial such as; increased platelet clearance due to splenomegaly, the suppressive effect of brucellosis bacteremia on bone marrow, hemophagocytosis, and peripheral autoimmune destruction. ${ }^{1,18,23}$ In a study that included five patients (2.6\% of all) with isolated thrombocytopenia during the course of acute brucellosis, an examination of bone marrow aspirate had revealed increment of megakaryocytes in two of these patients that may also be seen in idiopathic thrombocytopenic purpura. Authors suggested that; the mechanisms of thrombocytopenia may be destruction of thrombocytes by antibodies against Brucella organisms which cross react with thrombocytes. ${ }^{23}$ Whereas the pathogenesis of pancytopenia in brucellosis seems multifactorial, hypersplenism may be a possible explanation of pancytopenia in children infected with Brucella spp. In addition several possible mechanisms for pancytopenia such as hemophagocytosis (like that seen during the course of several infections including viral, bacterial, fungal and parasitic diseases), bone marrow hypoplasia, bone marrow granulomas, immune destruction, and the direct inhibitor effect of bacteria on bone marrow cells have been accused previously.,2,4,24 In a study from Turkey including children with brucellosis, pancytopenia had been found in 11 of the 52 patients $(21 \%)$ as the initial manifestation of brucellosis. One of these patients had presented with the complaint of nose bleeding and two patients had presented with gingival bleeding. More than a half of patients had hepatosplenomegaly. ${ }^{24}$ In a study including 146 children hospitalized due to brucellosis, $14(9.6 \%)$ had presented with hematologic manifestations, nine of them had pancytopenia and five had immune thrombocytopenia. Bone marrow aspiration and biopsy of the patients with pancytopenia revealed hypercellularity or severe hemophagocytosis. ${ }^{4}$ The present 
study's findings for hematological involvement frequency was in agreement with those previous reports. The most common findings following anemia were leukopenia and thrombocytopenia while the least common finding was pancytopenia which was detected in only four patients, similar as previous reported studies. Hemophagocytosis in bone marrow aspirate was detected in one of the our patients who had pancytopenia. Other four patients with hemophagocytosis presented with hematologic abnormalities in two series.

A study evaluating 511 brucellosis episodes reported that $42 \%$ of patients had cytopenia in at least one series. The authors demonstrated that older age $(10.49 \pm 4.81$ vs. $9.25 \pm 4.89$ years), fever $(92 \%$ vs. $78 \%)$, positive blood culture $(84 \%$ vs. $75 \%$ ), and $\operatorname{IgM} \geq 1: 640$ levels ( $50 \%$ vs. $39 \%$ ) were associated with the presence of cytopenia. The authors suggested that presence of fever and positive blood culture are the component of acute disease and high rates of cytopenia during acute brucellosis is a common finding. It was postulated that Brucella organisms suppress cell production in the bone marrow during bacteremia, especially when the bacterial load is high. ${ }^{18}$ Similary, a study of 69 children with brucellosis found a tendency to decrease platelet count in patients with bacteremic disease. ${ }^{2}$ In an another study including 123 brucellosis patients aged 13-73 years (60 patients with Brucella spp. bacteremia and 63 patients without bacteremia) revealed that, bacteremic patients presented with fever and chills more than nonbacteremic patients. In addition a significant elevation of AST and ALT concentrations and higher leukopenia rates were detected in bacteremic patients. ${ }^{25}$ On the contrary to previous reports ${ }^{18}$ we did not find any correlation between hematological involvement and age of patients, however in line with other previous reports ${ }^{2,18,25}$ we found a correlation between hematological involvement and presence of bactremia, fever, hepatosplenomegaly and elevated liver transaminase levels.

It is well known that, clinical and hematological improvement usually occurs within 2 to 3 weeks after the initiation of appropriate antimicrobial therapy. ${ }^{2,4}$ In addition, IVIg may be reserved as an emergent treatment for patients presented with hemophagocytosis or patients presented with severe bleeding symptoms and had symptoms of idiopathic thrombocytopenic purpura. ${ }^{4}$ We prescribed IVIg in addition to antimicrobial therapy in a total of six patients who presented with hemophagocytosis in bone marrow, severe thrombocytopenia, and hemolytic anemia.

In conclusion; we postulated that brucellosis should be considered in the differential diagnosis of patients presenting with one of the findings including fever, hepatosplenomegaly, elevated liver transaminase and hematologic abnormality at least in one series especially in endemic regions like our country. Hematological involvement in at least one cell lineage was a common finding (43.4\% of patients) regardless of age, especially in febrile, bacteremic patients and in patients who had hepatosplenomegaly and elevated liver enzymes. Anemia was the most common hematological abnormality, pancytopenia, severe thrombocytopenia and neutropenia were uncommon findings.

\section{Ethical approval}

This study was conducted in compliance with the ethical principles according to the Declaration of Helsinki, and it was approved by the Dr. Sami Ulus Maternity and Children's Health and Diseases Training and Research Hospital Institutional Review Board (Number: 2019/8).

\section{Author contribution}

The authors confirm contribution to the paper as follows: study conception and design: AK, FNÖ, AF; data collection: AK, SYD; analysis and interpretation of results: $\mathrm{AK}, \mathrm{AF}, \mathrm{GT}, \mathrm{TAT}$; draft manuscript preparation: AK, FNÖ, AF, TAT. All authors reviewed the results and approved the final version of the manuscript. 


\section{Source of funding}

The authors declare the study received no funding.

\section{Conflict of interest}

The authors declare that there is no conflict of interest.

\section{REFERENCES}

1. Karaman K, Akbayram S, Bayhan GI, et al. Hematologic findings in children with brucellosis: experiences of 622 patients in eastern Turkey. J Pediatr Hematol Oncol 2016; 38: 463-466. https://doi. org/10.1097/MPH.0000000000000612

2. Aypak A, Aypak C, Bayram Y. Hematological findings in children with brucellosis. Pediatr Int 2015; 57: 1108-1111. https://doi.org/10.1111/ped.12688

3. Young EJ. Brucella species (Brucellosis). In: Long SS, Ficher M, Prober CG (eds). Principles and practice of pediatric infectious diseases (5th ed). Philadelphia, PA: Elsevier, 2018: 861-865. https://doi.org/10.1016/ B978-1-4377-2702-9.00163-X

4. Citak EC, Citak FE, Tanyeri B, Arman D. Hematologic manifestations of brucellosis in children: 5 years experience of an Anatolian center. J Pediatr Hematol Oncol 2010; 32: 137-140. https://doi.org/10.1097/ MPH.0b013e3181ced382

5. Dallman PR. Blood and blood-forming tissue. In: Rudolph AM (ed). Pediatrics (16th ed). Norwalk, CT: Appleteon-Century-Crofts, 1977.

6. Boschiroli ML, Foulongne V, O'Callaghan D. Brucellosis: a worldwide zoonosis. Curr Opin Microbiol 2001; 4: 58-64. https://doi.org/10.1016/ S1369-5274(00)00165-X

7. Facciolà A, Palamara MAR, D'Andrea G, et al. Brucellosis is a public health problem in southern Italy: Burden and epidemiological trend of human and animal disease. J Infect Public Health 2018; 11: 861-866. https://doi.org/10.1016/j.jiph.2018.07.007

8. European Centre for Disease Prevention and Control. Brucellosis: Annual epidemiological report for 2017. Stockholm: ECDC, 2019 [cited October 11, 2021]. Available at: https://ecdc.europa. eu/en/publications-data/brucellosis-annualepidemiological-report-2017
9. T.C. Ministry of Health, General Directorate of Public Health, Department of Zoonotic and Vector Borne Diseases. Brucellosis statistics. [cited April 11, 2019]. Available at: http://www.thsk.gov.tr/ component/k2/353-istatiksel-veriler/zoonotik-vevektorel-hastaliklar-daire-baskanligi-istatikselverileri.html

10. Ma L, Ma J, Chen X, Dong L. A 10-year retrospective comparative analysis of the clinical features of brucellosis in children and adults. J Infect Dev Ctries 2021; 15: 1147-1154. https://doi.org/10.3855/ jidc. 13962

11. Çıraklı S, Karlı A, Şensoy G, Belet N, Yanık K, Çıraklı A. Evaluation of childhood brucellosis in the central Black Sea region. Turk J Pediatr 2015; 57: 123-128.

12. Parlak M, Akbayram S, Doğan $M$, et al. Clinical manifestations and laboratory findings of 496 children with brucellosis in Van, Turkey. Pediatr Int 2015; 57: 586-589. https://doi.org/10.1111/ped.12598

13. Çiftdoğan DY, Aslan S. Unrecognized pediatric and adult family members of children with acute brucellosis. Braz J Infect Dis 2017; 21: 520-524. https://doi.org/10.1016/j.bjid.2017.05.006

14. Xu D, Li X, Cheng B, et al. Congenital brucellosis: a case report. Vector Borne Zoonotic Dis 2021; 21: 727730. https://doi.org/10.1089/vbz.2021.0015

15. Carrera IA, Lopez Rodriguez MJ, Sapiña AM, et al. Probable transmission of brucellosis by breast milk. J Trop Pediatr 2006; 52: 380-381. https://doi. org/10.1093/tropej/fml029

16. Karakukcu M, Patiroglu T, Ozdemir MA, Güneş T, Gümüş H, Karakucu Ç. Pancytopenia, a rare hematologic manifestation of brucellosis in children. J Pediatr Hematol Oncol 2004; 26: 803-806.

17. Fruchtman Y, Segev RW, Golan AA, et al. Epidemiological, diagnostic, clinical, and therapeutic aspects of Brucella bacteremia in children in southern Israel: a 7-year retrospective study (20052011). Vector Borne Zoonotic Dis 2015; 15: 195-201. https://doi.org/10.1089/vbz.2014.1726

18. Justman N, Fruchtman Y, Greenberg D, Ben-Shimol S. Hematologic manifestations of brucellosis in children. Pediatr Infect Dis J 2018; 37: 586-591. https://doi.org/10.1097/INF.0000000000001900

19. Fanni F, Shahbaznejad L, Pourakbari B, Mahmoudi S, Mamishi S. Clinical manifestations, laboratory findings, and therapeutic regimen in hospitalized children with brucellosis in an Iranian Referral Children Medical Centre. J Health Popul Nutr 2013; 31: 218-222. https://doi.org/10.3329/jhpn.v31i2.16386 
20. Akdeniz H, Irmak H, Seckinli T, et al. Hematological manifestations in brucellosis cases in Turkey. Acta Med Okayama 1998; 52: 63-65.

21. al-Eissa $Y$, al-Nasser M. Haematological manifestations of childhood brucellosis. Infection 1993; 21: 23-26. https://doi.org/10.1007/BF01739305

22. Akya A, Bozorgomid A, Ghadiri K, et al. Usefulness of blood parameters for preliminary diagnosis of brucellosis. J Blood Med 2020; 11: 107-113. https:// doi.org/10.2147/JBM.S245513

23. Akbayram S, Dogan M, Akgun C, Peker E, Parlak $\mathrm{M}$, Oner AF. An analysis of children with brucellosis associated with isolated thrombocytopenia. Clin Appl Thromb Hemost 2011; 17: e36-e38. https://doi. org/10.1177/1076029610382104
24. Karli A, Sensoy G, Albayrak C, et al. Pancytopenia As the initial manifestation of brucellosis in children. Vector Borne Zoonotic Dis 2015; 15: 545-549. https:// doi.org/10.1089/vbz.2015.1775

25. Kadanali A, Ozden K, Altoparlak U, Erturk A, Parlak M. Bacteremic and nonbacteremic brucellosis: clinical and laboratory observations. Infection 2009; 37: 67-69. https://doi.org/10.1007/s15010-008-7353-3 